\title{
A Case-Control Study of Obstetric Risk Factors for Low Birth Weights and Preterm Births
}

\author{
Irena Hristova ${ }^{1 *}$, Joana Simeonova ${ }^{2}$, Nadezdha Hinkova $^{3}$, Slavcho Tomov $^{4}$ \\ ${ }^{1}$ Assistant Professor, Department of Midwifery, Faculty of Health Care, Medical University - Pleven, 1, St. Kliment Ohridski, 5800 Pleven, Bulgaria \\ ${ }^{2}$ Assistant Professor, Department of Social Medicine, Faculty of Public Health, Medical University - Sofia, 8, Bialo More, Sofia, Bulgaria \\ ${ }^{3}$ Associate Professor, Department of Midwifery, Faculty of Health Care, Medical University Pleven, Bulgaria \\ ${ }^{4}$ Professor, Department of Midwifery, Faculty of Health Care, Medical University - Pleven, Bulgaria
}

DOI: $10.36348 /$ sjmps.2020.v06i01.004

| Received: 30.12.2019| Accepted: 06.01.2020 | Published: 15.01.2020

*Corresponding author: Irena Hristova

\section{Abstract}

To study the role of the obstetric risk factors for low birth weight and preterm birth. A case-control study was carried out in 2017 at the University Hospital - Pleven; 1212 women in childbirth and 1212 live-born babies after single pregnancies were included in the study. The live-born infants were divided into two groups. The cases included the preterm low-birthweight (PLBW) newborns weighing less than 2500 grams $(\mathrm{g})$. The controls included full-term newborns with normal birth weight (FTNBW). The role of 8 obstetric risk factors (RFs) on PLBW was studied (maternal age, type of birth, amniotic fluid deficiency and congenital abnormalities, maternal pelvic size abnormalities, placental abnormalities, abnormalities of fetal membranes, umbilical cord abnormalities, and presentation of the fetus). The obstetric RFs were significantly associated with PLBW. Risk of PLBW is significantly higher $(\mathrm{p}=0.001)$ in breech presentation (exp $(\beta)=6.622)$, placental abnormalities $(\exp (\beta)=5.556)$, maternal pelvic size abnormalities $(\exp (\beta)=4.426)$ and amniotic fluid deficiency and congenital abnormalities $(\exp (\beta)=2.903)$. The results of that study can be useful for effecting prevention programing of pregnancy and prematurity.

Keywords: women in childbirth, preterm low-birth-weight, newborns, breech presentation, placental abnormalities, maternal pelvic size abnormalities, amniotic fluid deficiency and congenital abnormalities, binary logistic regression.

Copyright @ 2020: This is an open-access article distributed under the terms of the Creative Commons Attribution license which permits unrestricted use, distribution, and reproduction in any medium for non-commercial use (NonCommercial, or CC-BY-NC) provided the original author and source are credited.

\section{INTRODUCTION}

Prematurity has more significant impact on the physical development of the children and has been one of leading global burden of disease [1-6]. Preterm babies have a high risk for neurological diseases, more common problems with vision and learning deficits [7] and chronic non-communicable diseases in adulthood [8-12].

Prematurity birth rates reported in different populations range between $9 \%$ and $50 \%$. In Bulgaria, these rates have increased from $6.1 \%$ in 80 years of 20 th century $(6.1 \%$ in EU, $5.5 \%$ in Norway, $4.1 \%$ in Finland) to $8.1 \%$ in 2011 ; these values were higher compared with the lowest values in Europe (Norway $4.8 \%$, Finland $-4.1 \%$ ) and lower compared with the highest European values (Cyprus - 13.1\%) [1, 4, 7, 1317].

Over the last 20 years, no comprehensive assessment has been made of risk factors for premature birth and low birth weight despite the fact that it is associated with the all costs which are paid by preterm newborns, their families and society [13].

The study aimed to evaluate the role of the obstetric RFs for low birth weights and preterm births.

\section{MATERIAL AND METHODS}

The case-control study was carried out in 2017 at the University Hospital - Pleven; it was a part of dissertation and approved by Research Ethics Committee.

The study included 1212 women in childbirth (26.6 \pm 6.5 years) and 1212 live-born babies after single pregnancies were included in the study. Inclusion criteria were: women in childbirth and live-born infants should be registered at the University hospital in Pleven in 2017 and data collected for the study should be available. We did not include 37 full-term low-birthweight (FTLBW) newborns and 100 preterm births with 
normal birth weight (PNBW) newborns in the study to control confounding effects.

The live-born infants were divided into two groups: cases and controls. The cases included the preterm low-birth-weight (PLBW) newborns born before 37 gestational weeks $(\mathrm{GW})$ and weighing less than 2500 grams $(\mathrm{g})$. The control group included fullterm newborns with normal birth weight (FTNBW). The study did not include 37 full-term low-birth-weight (FTLBW) newborns and 100 preterm with normal birth weight (PNBW) newborns to control confounding effects.

Data were collected from the pregnancy history about: last menstrual period (LMP) estimated the date of confinement (EDC) and date of birth to estimate gestational age. The gestational age was measured in GW and calculated from the first date of the LMP. Birth weight of babies was measured immediately after delivery with weighing scales with 1 g accuracy.

We gathered information about 8 obstetric RFs: maternal age, type of birth (vaginal birth or
Caesarean section), amniotic fluid deficiency and congenital abnormalities, maternal pelvic size abnormalities, placental abnormalities (yes/no), abnormalities of fetal membranes (yes/no), umbilical cord abnormalities (yes/no), and presentation of the fetus (cephalic presentation, breech presentation, transverse presentation, etc.).

Data were processed by SPSS v.24.0. ANOVA and Pearson Chi-square were used. We assumed the differences between groups as significant if the $\mathrm{p}$-value was less than or equal to 0.05 . Maternal age was studied as continuous variable (Mean and standard deviation, SD). Binary logistic regression was used to determine the risk factors affecting the PLBW. All other variables, included in the analysis, were categorical variables and displayed as number of cases and percentage.

\section{RESULTS}

The mean age of the women in childbirth was $26.6 \pm 6.5$ years. The youngest woman in childbirth was 14 years old, and the oldest -46 years old. Most of them $(56.08 \%)$ were urban residents and single (73.52\%, Table 1).

Table-1: Distribution of the women in childbirth by sociodemographic characteristics (Number, \%)

\begin{tabular}{|l|l|l|l|l|l|}
\hline Variable & Number & $\mathbf{\%}$ & Variable & Number & \% \\
\hline Age & & & Place of residence & & \\
Mean age & $26.6 \pm 6.5$ & & Urban & 678 & 56.08 \\
Under19 years & 193 & 15.93 & Rural & 531 & 43.92 \\
20-35 years & 862 & 71.12 & Total & $\mathbf{1 2 0 9 *}$ & $\mathbf{1 0 0 . 0 0}$ \\
Over 35 years & 157 & 12.95 & & & \\
Total & $\mathbf{1 2 1 2}$ & $\mathbf{1 0 0 . 0 0}$ & & & \\
\hline Education & & & Marital status & 698 & 26.48 \\
Illiterate & 128 & 10.60 & Married & 513 & 73.52 \\
Primary school (grades 1-4) & 139 & 11.51 & Single & $\mathbf{1 2 0 1} *$ & $\mathbf{1 0 0 . 0 0}$ \\
Middle school (grades 1-8) & 231 & 19.12 & Total & & \\
Secondary education & 440 & 36.42 & & & \\
Higher education & 270 & 22.35 & & $\mathbf{1 2 1 2}$ & $\mathbf{1 0 0 . 0 0}$ \\
Total & $\mathbf{1 2 0 8 *}$ & $\mathbf{1 0 0 . 0 0}$ & & Total \\
\hline \multicolumn{2}{|l|}{} & &
\end{tabular}

*There is no data about some respondents up to 1212

The women with secondary and higher education were $58.77 \%$. PLBW newborns were 120 or $9.90 \%$ of all cases (Table 2). The mean maternal age was significantly higher $(28.0 \pm 7.4)$ in the group of the PTLBW compared to the other three groups $(\mathrm{p}=0.02)$. 
Irena Hristova et al; Saudi J Med Pharm Sci, Jan., 2020; 6(1): 26-31

Table-2: Distribution of live-born infants by obstetric characteristics of women in childbirth

\begin{tabular}{|c|c|c|c|c|c|}
\hline $\begin{array}{l}\text { Groups of live-born infants } \\
\text { Obstetric characteristics } \\
\end{array}$ & $\begin{array}{l}\text { PNBW } \\
(\mathrm{n}=100 \\
\mathbf{8 . 2 5} \%)\end{array}$ & $\begin{array}{l}\text { PLBW } \\
(\mathbf{n = 1 2 0} \\
9.90 \%)\end{array}$ & $\begin{array}{l}\text { FTNBW } \\
(\mathbf{n}=955 ; \\
\mathbf{7 8 . 8 0 \%})\end{array}$ & $\begin{array}{l}\text { FTLBW } \\
(\mathbf{n = 3 7} \\
\mathbf{3 . 0 5 \%})\end{array}$ & $\mathbf{p}$ \\
\hline $\begin{array}{l}\text { Age } \\
\text { Mean age } \pm S D\end{array}$ & $26.4 \pm 6.7$ & $28.0 \pm 7.4$ & $26.5 \pm 6.3$ & $26.5 \pm 7.8$ & 0.020 \\
\hline $\begin{array}{l}\text { Type of birth } \\
\text { Cesarean birth }(\%)\end{array}$ & 33.00 & 58.30 & 39.00 & 48.00 & 0.001 \\
\hline $\begin{array}{l}\text { Maternal pelvic dimensions } \\
\text { Anatomically narrow pelvis }(\%)\end{array}$ & 5.00 & 8.00 & 2.57 & 7.14 & 0.001 \\
\hline $\begin{array}{l}\text { Amniotic fluid } \\
\text { Amniotic fluid deficiency and congenital abnormalities } \\
(\%)\end{array}$ & 37.11 & 44.35 & 19.45 & 22.22 & 0.001 \\
\hline $\begin{array}{l}\text { Placenta } \\
\text { Placental abnormalities }(\%)\end{array}$ & 8.89 & 20.0 & 5.58 & 25.71 & 0.001 \\
\hline $\begin{array}{l}\text { Fetal membranes } \\
\text { Abnormalities of fetal membranes }(\%)\end{array}$ & 1.05 & 2.59 & 1.31 & 2.70 & 0.641 \\
\hline $\begin{array}{l}\text { Umbilical cord } \\
\text { Umbilical cord abnormalities }(\%)\end{array}$ & 32.29 & 25.86 & 28.13 & 11.11 & 0.101 \\
\hline $\begin{array}{l}\text { Presentation of the fetus } \\
\text { Breech presentation }(\%)\end{array}$ & 3.06 & 21.82 & 3.66 & 16.22 & 0.001 \\
\hline
\end{tabular}

*There were 4 groups of newborns: PNBW-preterm with normal birth weight, PLBW-preterm low-birth-weight, FTNBW-full-term newborns with normal birth weight, FTLBW-full-term low-birth-weight,

The proportion of PLBW was significantly $(\mathrm{p}<0.005)$ higher in caesarean births $(58.30 \%)$, breech presentation of the fetus $(21.82 \%)$, maternal pelvic size abnormalities $(8.00 \%)$ amniotic fluid deficiency and congenital abnormalities (44.35\%) and placental abnormalities (20.00\%).

Results from a binary logistic regression were presented in Table 3.

Table-3: Potential prognostic RFs for PLBW (Forward LR of binary logistic regression)

\begin{tabular}{|l|c|c|c|c|c|c|}
\hline Variable & $\boldsymbol{\beta}$ & $\mathbf{S E}$ & $\mathbf{d f}$ & $\mathbf{S i g} \cdot$ & $\begin{array}{l}\text { Exp } \\
(\boldsymbol{\beta})\end{array}$ & $\begin{array}{l}\mathbf{9 5 \%} \text { CI for Exp } \\
(\boldsymbol{\beta})\end{array}$ \\
\hline $\begin{array}{l}\text { Anatomically narrow pelvis (a reference category: normal } \\
\text { size of the pelvis) }\end{array}$ & 1.489 & 0.467 & 1 & 0.001 & 4.432 & $1.775 \div 11.069$ \\
\hline $\begin{array}{l}\text { Placental abnormalities (a reference category: normal } \\
\text { placenta) }\end{array}$ & 1.716 & 0.307 & 1 & 0.001 & 5.562 & $3.045 \div 10.160$ \\
\hline $\begin{array}{l}\text { Amniotic fluid deficiency and congenital abnormalities } \\
\text { reference category: normal amniotic fluid) }\end{array}$ & 1.073 & 0.238 & 1 & 0.001 & 2.924 & $1.833 \div 4.664$ \\
\hline $\begin{array}{l}\text { Presentation of the fetus } \\
\text { reference category: cephalic presentation) }\end{array}$ & 1.891 & 0.338 & 1 & 0.001 & 6.625 & $3.413 \div 12.862$ \\
\hline
\end{tabular}

The model correctly predicted $87.5 \%$ of the cases. The risk for preterm low-birth weight newborn was about 3 times higher in premature amniotic fluid rupture. The risk increased up to 4.4 times in women with anatomically narrow pelvis, about 6 times in women with placental abnormalities and 7 times - in breech presentation of the fetus.

\section{DISCUSSION}

Obstetric RFs have an important role on the multifactorial etiology of prematurity, as: multiple pregnancies which associated with assist reproductive technologies (ART), breech presentation of the fetus, placenta previa, premature amniotic fluid rupture, inducing labor for medical causes, multiple parity [2, 17-22].
In the Bulgarian National Health Strategy (2014-2020) premature babies are specify as priority group (5048 or $8.8 \%$ in 2013); and one of the main goals in that document is to create an effective monitoring for premature babies [23]. However, more preventive care on prematurity in Bulgaria is focused on tertiary prevention [21]. There is a deep gap to reduce of premature rates by early and complete coverage of high-risk pregnancies (including biochemical and ultrasound screening); although it is more difficult to realize that [21, 23]. Effective prevention is also requiring complex approach and health care should be focused both on the pregnant women, women in child-birth and infants (0-1 years) [21]. 
Irena Hristova et al; Saudi J Med Pharm Sci, Jan., 2020; 6(1): 26-31

A few previous studies have revealed that the risk of preterm birth in younger (under 17- or 19-year of age) and older women in child-birth (after aged 3540 years) increases [2, 17, 19, 24-27]. As others, we found that the mean maternal age was significantly higher in the group of PLBW newborns (28.0 \pm 7.4$)$ compared with the group of FTNBW newborns (26.5 \pm 7.8$)$. However, some publications have been distinguished from ours $[2,16,22]$. The risk of preterm birth in girls less than 19-year-old is associated with biological immaturity and low gynecological age [20]; they lead to more common anaemia and genital tract inflammation [2]. In women aged 30 years and older, the higher rates of preterm birth are associated with more common pregnancy complications, as well as changes in anatomy and physiology of the female reproductive system which speed up labor [18].

Over $58 \%$ of PLBW infants in the study were cesarean-born, and binary logistic regression shown $\operatorname{Exp}(\beta)=1.585$ and marginal significant $p$-value $(\mathrm{p}=0.055)$. Similar results were reported by M. Sandeva (2019): the proportion of the abdominal delivery in PLBW newborns was in range 58-70.8\%, Cesarean section was a RF for preterm low-birth-weight baby $(\mathrm{OR}=2.51, \mathrm{p}=0.06)$ [16]. Decision-making for Cesarean section in preterm birth depends on the length of pregnancy and characteristics of the study population (from 22-23 GW in Germany and Denmark to 28-29 GW in France, Italy and United Kingdom) [18]. In women less than 19-year-old and older than 35, type of birth is determined by the doctors' belief that these age groups are high-risk groups [5]. In younger, cesarean sections were due to acceleration and the associated Cephalopelvic disproportion $[1,2,6,7,12]$. In cases when the first pregnancy occurs in age 30 years and older, the higher rates of abdominal delivery are determined by two RFs: more common complications of pregnancy and "phenomenon of aging" [18].

We found that about $10 \%$ of PLBW occurred in women in child-birth in which maternal pelvic size abnormalities were available. It has been proven that the growth and development of the female pelvis are not complete at the age of 19 and that are slower as compared with height growth, especially in young women [1, 7]. The results established for maternal pelvic size abnormalities in populations in individual countries vary, including ethnic groups differences within countries $[1,6]$. This warrants the assumption that maternal pelvic size abnormalities could not be used as a reliable measure in comparative analyses of prematurity.

Most obstetricians prove that vaginal delivery of premature baby in breech presentation as a high-risk and recommend Cesarean section. The prevalence of Cesarean sections in cases of the preterm breech presentation delivery was high (range 63.9-87.0\%) and often is due to obstetric RFs and complications of the pregnancy threatened both the life of mother and child [18]. Over $20 \%$ of PLBW cases in our study were associated with the breech presentation of the fetus, and that increased the risk of premature baby about 7 times. In the case-control study Jiant et al. (2018) found that the breech presentation of the fetus has been a RF for PLBW $(\operatorname{Exp}(\beta)=3.383,95 \% \mathrm{CI}=1.623 \div 7.054)[20]$.

It has been found that the prevalence of preterm births was a high in placenta previa and the placenta implantation abnormalities are more common present with vaginal bleeding. It has been a powerful predictive value for premature baby which was associated with both two RFs [2]. One-fifth of PLBW in the study associated with the placental abnormalities, there were statistically significant differences, and the risk for PLBW was over 5 times higher compared with the women in child-birth that had normal placenta. Similar results we found in some publications $[9,15$, $16,18,22,28]$. Between $25 \%$ and $40 \%$ of preterm births were associated with the premature amniotic fluid rupture [9]. As others [9, 15, 28], we found that the proportion of PLBW was over $40 \%$ in cases of premature amniotic fluid rupture, the risk for preterm birth and birth weight less than $2500 \mathrm{~g}$ was 3 times higher $(\operatorname{Exp}(\beta)=2.903,95 \% \mathrm{CI}=1.817 \div 4.638)$ compared with those who had preserving amniotic fluid. Premature amniotic fluid rupture increases risk for perinatal infections [21]. Abnormalities of fetal membranes (polyhydramnios and oligohydramnios) are RFs for preterm birth [21]. Like Jiant et al. [18], we confirmed the null hypothesis: there were no statistically significant differences in groups according to abnormalities of fetal membranes and PLBW $(\mathrm{p}>0.05)$.

\section{CONCLUSION}

That study confirms the others about complex and heterogenic etiology of the preterm birth. One of the strength, this is case-control study design because it is possible to identify many obstetric RFs which prevalence is different in the study groups. The second strength, this is using of the binary logistic regression and clarify the potential prognostic RFs for PLBW (maternal pelvic size abnormalities, amniotic fluid deficiency and congenital abnormalities, placental abnormalities, and presentation of the fetus); the logistic regression model has a high prognostic value.

It was not clear the role of the confounders (age and social status) on statistical model and we think that is a weakness of the study. We want to continue our research work, and we will study the role of medico-social RFs on the PLBW in stratified sampling (age, educational and stratification according to professional status). The specific conditions and opportunities of antenatal care in our country and each health region should be taken into account in the future 
scientific work because of their role on the preterm birth and low birth weight.

The obstetric RFs for preterm birth before than $37 \mathrm{GW}$ and birth weight less than $2500 \mathrm{~g}$ are very different and require to be identified during the pregnancy. Such an approach could considerably reduce the risk of premature birth and associated ьаэеияе outcomes on the preterm babies, their families, health system and society. On the other hand, health technologies make possible to use blood tests to predict the risk of preterm birth.

The results from the study could be used in programs addressing the prevention and management of pregnancy and prematurity. Those programs should be focused on the long-term adverse health conditions as retinopathy, COPD, total loss of hearing and vision cognitive deficits, cerebral palsy type 2 diabetes mellitus, hypertension, ischemic heart disease.

\section{ACKNOWLEDGEMENTS}

This study is a part of thesis and has no received financial support.

\section{REFERENCES}

1. Dimitrov, A. (2014). [Obstetrics]. Sofia: ARSO. Bulgarian.

2. Karamisheva, V. (2016). [Assessment of risk and approach in preterm birth] [Dissertation]. Sofia: Medical University. Bulgarian.

3. Katsulov, A. (1989). [High-risk pregnancy]. Sofia: Medicina i Fizkultura. Bulgarian.

4. Katsulov, A. (1990). [High-risk birth]. Sofia: Medicina i Fizkultura. Bulgarian.

5. Carmichael, S., Abrams, B. (1997). A critical review of the relationship between gestational weight gain and preterm delivery. Obstetrics and Gynecology, 89(5), 865-873.

6. Maness, S.B.., Buhi, E.R., Daley, E.M., Baldwin, J.A., Kromrey, J.D. (2016). Social determinants of health and adolescent pregnancy: an analysis from the National Longitudinal Study of Adolescent to Adult Health. Journal of Adolescent Health, 58(6), 636-643.

7. Vakrilova, L. (2011). Early criteria for risk assessment and prognosis in neonates with birth weight less than $1500 \mathrm{~g}$. [dissertation], Sofia: Medical University. Bulgarian.

8. Kambourova, M., Hristova, I. (2014). [Maternal effects on preterm birth]. Journal of Obstetrics and Gynaecology, 3(53), 29-33. Bulgarian.

9. Ivanov, S. (2013). [Preterm birth and premature infant - the challenges to Obstetrics and Gynecology]. Health. Bg, 5, 12-15. Bulgarian.

10. Boots, A.B., Sanchez-Ramos, L., Bowers, D.M., Kaunitz, A.M., Zamora, J., Schlattmann P. (2014). The short-term prediction of preterm birth: a systematic review and diagnostic meta-analysis.
American Journal of Obstetrics \& Gynecology, $10(1), 54 \mathrm{e} 1-54 \mathrm{e} 10$.

11. Linsell, L., Malouf, R., Morris, J., Kurinczuk, J.J., Marlow, N. (2015). Prognostic factors for poor cognitive development in children born very preterm or with very low birth weight: a systematic review. JAMA Pediatrics, 169(12), 1162-1172.

12. Mercer, BM., Goldenberg, R.L., Das, A., Moawad, A.H., Iams, J.D., Meis, P.J., Copper, R.L., Johnson, F., Thom, E., McNellis, D., Miodovnik, M., Menard, M.K., Caritis, S.N., Thurnau, G.R., Bottoms, S.F., Roberts, J. (1996). The preterm prediction study: a clinical risk assessment system. American Journal of Obstetrics \& Gynecology, 174(6), 1885-1893.

13. Kambourova, M. (2014). Risk factors for premature birth and the effect on the health and social needs of premature children for their development before the age of three. [dissertation]. Pleven: Medical University. Bulgarian.

14. Asvanarunat, E. (2014). Outcomes of gestational weight gain outside the Institute of Medicine Guidelines. Journal of the Medical Association of Thailand, 97(11), 1119-1125.

15. Kolev, N. (2014). [Biochemical changes and transvaginal ultrasound in preterm birth]. [dissertation]. Varna: Medical University. Bulgarian.

16. Sandeva, M. (2019). [Prevalence and medico-social aspects of preterm birth]. [dissertation]. Plovdiv: Medical University. Bulgarian.

17. Stylianou-Riga, P., Kouis, P., Kinni, P., Rigas, A., Papadouri, T., Yiallouros, PK., Theodorou, M. (2018). Maternal socioeconomic factors and the risk of premature birth and low birth weight in Cyprus: a case-control study. Reproductive Health. $15,157$.

18. Yankova, Y. (2012). [Labor in preterm birth]. [Dissertation]. Sofia: Medical University. Bulgarian.

19. Ivanov, I. (2019). [Screening of preterm birth] [dissertation]. Pleven: Medical University. Bulgarian.

20. Jiang, M., Mishu, M.M., Lu, D., Yin, X. (2018). A case control study of risk factors and neonatal outcomes of preterm birth. Taiwan Journal of Obstetrics and Gynaecology, 57, 814-818.

21. Ivanov, I. Prevention of preterm birth. (2018). Journal of Biomedical and Clinical Research. 11(2), 95-104.

22. Leal, M-C., Esteves-Pereira, A., Nakamura-Pereira, Torres, J., Theme-Filha, M., Domingues, R., Bastos Dias, M.A., Moreira, M.E., Gama, S.G. (2017). Prevalence and risk factors related to preterm birth in Brazil. Reproductive Health, 13(Suppl 3), 163-174.

23. Ministry of Health. [Bulgarian National Health Strategy (2014-2020)]. [Internet]. Retrieved May 17, 2019, from: 
https://www.mh.government.bg/media/filer_public/ 2015/06/26/proekt-nacionalna-zdravna-strategiq2014-2020.pdf. Bulgarian.

24. Traisrisilp, K., Jaiprom, J., Luewan, S., Tongsong, T. (2015). Pregnancy outcomes among mothers aged 15 years or less Journal of Obstetrics and Gynaecology Research. 41(11), 1726-1731.

25. Kovacheva-Chincheva, S. (1997). [Social and medical problems of pregnancy and birth in aged under 19 years] [dissertation], Blagoevgrad: SouthWest University „Neofit Rilski“. Bulgarian.

26. Popov, Y. (1990). [Pregnancy and birth of first child in old women] [Dissertation]. Pleven: Medical University. Bulgarian.
27. Kozuki, N., Lee, A.C., Silveira, M.F., Sania, A., Vogel, J.P., Adair, L., Barro, S.F., Caulfield, L.E., Christian, P., Fawzi, W., Humphrey, J., Huybregts, L., Mongkolchati, A., Ntozini, R., Osrin, D., Roberfroid, D., Tielsch, J., Vaidya, A., Black, R.E., Katz, J., Child Health Epidemiology Reference Group Small-for-Gestational-Age-Preterm Birth Working Group. (2013). The associations of parity and maternal age with small-for-gestational-age, preterm, and neonatal and infant mortality: a metaanalysis. BMC Public Health. Suppl 3:S2.

28. Halimi, A.S., Safari, S., Parvareshi, Hamrah, M. (2017). Epidemiology and related risk factors of preterm labor as an obstetrics emergency. Emergency (Tehran, Iran), 5(1):e3. 